Stephen M. Koch MD, David C. Abramson, MBChB FFA, Michael Ford MD, David Peterson MD, Jeffrey Katz MD

\title{
Bronchoscopic findings in post-obstructive pulmonary oedema
}

Purpose: To present the first photographed bronchoscopic findings associated with negative pressure pulmonary oedema (NPPE).

Clinical features: A previously healthy patient underwent anterior $C_{.5}-C_{4}$ disc removal and arthrodesis. Following tracheal extubation he developed acute respiratory distress manifested as stridor, tachypnoea, restlessness, and desaturation. Once the trachea was reintubated, he displayed the classic findings of pulmonary oedema. Bronchoscopy was performed to confirm tracheal tube position and to rule out tracheal injury secondary to surgical manipulation. Diffuse punctate haemorrhages were noted throughout the visualised tracheobronchial tree.

Conclusion: We believe that these haemorrhages represent disruption of the bronchial vasculature and may contribute to the clinical presentation of NPPE.

Objectif: Présenter les premières photographies par bronchoscopie d'un oedème pulmonaire provoqué par une pression pulmonaire négative.

Eléments clniques: Un patient jusque là bien portant subit une résection antérieure de disque à $C_{5}-C_{4}$ avec arthrodèse. Après l'extubation de la trachée, il développe une détresse respiratoire aiguë manifestée par du stridor, de la tachypnée, de l'agitation et de la désaturation. Une fois réintubé, il révèle les signes classiques d'un oedème pulmonaire. Une bronchoscopie est réalisée pour confirmer la position du tube endotrachéal et d'éliminer la possibilité de blessure trachéale secondaire à la manipulation chirurgicale. Des hémorragies diffuses ponctiformes sont notées sur l'arbre trachéobronchique.

Conclusion: Nous croyons que ces hémorragies représentent la rupture de la vasculature bronchique et peuvent contribuer aux manifestations cliniques d'un oedème pulmonaire associé à une pression pulmonaire négative.

\section{Key words}

COMPLICATIONS: pulmonary oedema; LUNG: bronchoscopy.

From the Department of Ancsthesiology, The University of Texas Medical School, Houston, TX 77030

Address correspondence 10: Dr. Stephen M. Koch, The University of Texas Medical School, Department of Anesthesiology, 6431 Fannin, MSB 5.020, Houston, TX 77030

Accepted for publication 28th September, 1995.
Transient, self-limited non-cardiogenic pulmonary oedema occurring immediately or shortly after relief of acute upper airway obstruction has been the subject of several case reports and review articles. ${ }^{1-5}$ Typically, a young, healthy patient develops transient upper airway obstruction after postoperative tracheal extubation, leading to abrupt development of pulmonary oedema. This form of pulmonary oedema has been termed negative pressure pulmonary oedema (NPPE) and usually resolves over the ensuing several hours with supportive measures.

We report a case of postobstructive acute pulmonary oedema during the management of which we had the opportunity to photograph the tracheobronchial mucosa.

\section{Case report}

A 42-yr-old man with a two year history of progressive upper and lower extremity weakness due to cervical cord compression was scheduled for anterior $\mathrm{C}_{3-4}$ disc removal and arthrodesis. There was no other medical history. He was a non-smoker and denied any reflux symptoms. He weighed $75 \mathrm{~kg}$ and was $1.65 \mathrm{~m}$ tall. He denied allergies and was taking no medication. On examination, he was apyrexial, had a blood pressure (BP) of $114 / 85 \mathrm{mmHg}$ with a heart rate (HR) of 94 beats per minute (bpm).

The day before surgery, an intravenous line was placed and a regimen of steroid infusion (methylprednisolone) was commenced; this continued throughout the period of surgery at a fixed rate. He was given premedication of meperidine $75 \mathrm{mg} i m$ and promethazine $25 \mathrm{mg}$ im and diazepam $10 \mathrm{mg}$ po one hour before anaesthesia.

On arrival in the operating room, ECG electrodes were placed, an automatic blood pressure cuff and a pulse oximeter finger probe were applied. Initial BP was $138 / 85 \mathrm{mmHg}$ and $\mathrm{HR}$ was $\mathrm{I} 25 \mathrm{bpm}$; oxygen saturation breathing room air was $100 \%$.

After the application of oxygen by facemask, anaesthesia was induced with thiopentone $425 \mathrm{mg}$, sufentanil $20 \mu \mathrm{g}$ and midazolam $2 \mathrm{mg} i v$. With loss of consciousness and the ability to ventilate the lungs by mask, vecuronium $10 \mathrm{mg}$ iv was given to facilitate tracheal intubation which was achieved atraumatically with a 7.5 $\mathrm{mm}$ internal diameter polyvinylchloride tube with a high 
volume, low pressure balloon cuff after easy visualization of the vocal cords. Bilateral breath sounds were auscultated and correct positioning of the tracheal tube was confirmed with a normal capnograph trace. An orogastric tube was passed and an oesophageal temperature probe was placed. The lungs were ventilated to maintain $\mathrm{PETCO}_{2}$ between 3.6 and $4.8 \mathrm{kPa}$.

Anaesthesia was maintained with isoflurane in nitrous oxide and oxygen (1.5\% initially, reducing to between $0.4 \%$ and $0.8 \%$ ) delivered via a circle absorber breathing circuit with a fresh gas flow of $5 \mathrm{~L} \cdot \mathrm{min}^{-1}$. Vecuronium was given incrementally to maintain neuromuscular paralysis.

Immediately following induction, the BP settled to $90 / 55 \mathrm{mmHg}$, the HR slowed to the range of 70 to 80 bpm (sinus rhythm) for the next two hours and the $\mathrm{SpO}_{2}$ remained between $95 \%$ and $99 \%$ throughout the case. Temperature ranged between 35.4 and $35.8^{\circ} \mathrm{C}$.

At the completion of surgery, which lasted approximately $150 \mathrm{~min}$, neuromuscular blockade was reversed with neostigmine $3 \mathrm{mg} i v$ and glycopyrrolate $0.6 \mathrm{mg} i v$ given approximately $30 \mathrm{~min}$ after the last $1 \mathrm{mg}$ bolus dose of vecuronium. Once spontaneous respiration resumed he was given lidocaine $75 \mathrm{mg}$ iv prior to awake tracheal tube extubation in the operating room. He was taken to the post-anaesthesia care unit in halo traction, where the initial BP recorded was $150 / 80 \mathrm{mmHg}$, pulse $110 \mathrm{bpm}$ and oxygen saturation with supplemental face mask oxygen was $95 \%$. Coarse breath sounds were heard over both lung fields. He complained of pain and shortness of breath and was observed to be restless and agitated. Incremental doses of morphine (total $6 \mathrm{mg} i v$ ) and midazolam were given in response.

Rapid onset of acute respiratory distress associated with an $\mathrm{SpO}_{2}$ of $85 \%$ despite $100 \%$ supplemental $\mathrm{O}_{2}$ by non-rebreathing mask developed over the next few minutes. Stridor was noted over the suprasternal notch with considerable respiratory efforts without auscultory evidence of air movement. Copious pink and frothy material exuded from both the mouth and the nares. Arterial blood gases showed pH 7.13, $\mathrm{PaO}_{2} 14.3 \mathrm{kPa}(107$ $\mathrm{mmHg}$ ), $\mathrm{PaCO}_{2} 7.3 \mathrm{kPa}$ (55 $\mathrm{mmHg}$ ), $\mathrm{HCO}_{3}^{-} 19$ $\mathrm{mmol} \cdot \mathrm{L}^{-1}$ and base excess -1 . The acidosis and deteriorating mental status prompted awake nasal intubation. $\mathrm{A}$ presumptive diagnosis of pulmonary oedema was made and furosemide $40 \mathrm{mg} i v$ was administered, in addition to the $100 \%$ oxygen.

Bronchoscopy (Olympus, Dallas, TX) was performed soon afterwards to confirm the position of the blindly placed tracheal tube and to rule out tracheal injury secondary to surgical manipulation. All tracheo-bronchial secretions were suctioned under direct - vision; there were no periods of desaturation during the procedure (saturation remained above $95 \%$ throughout). Photo-

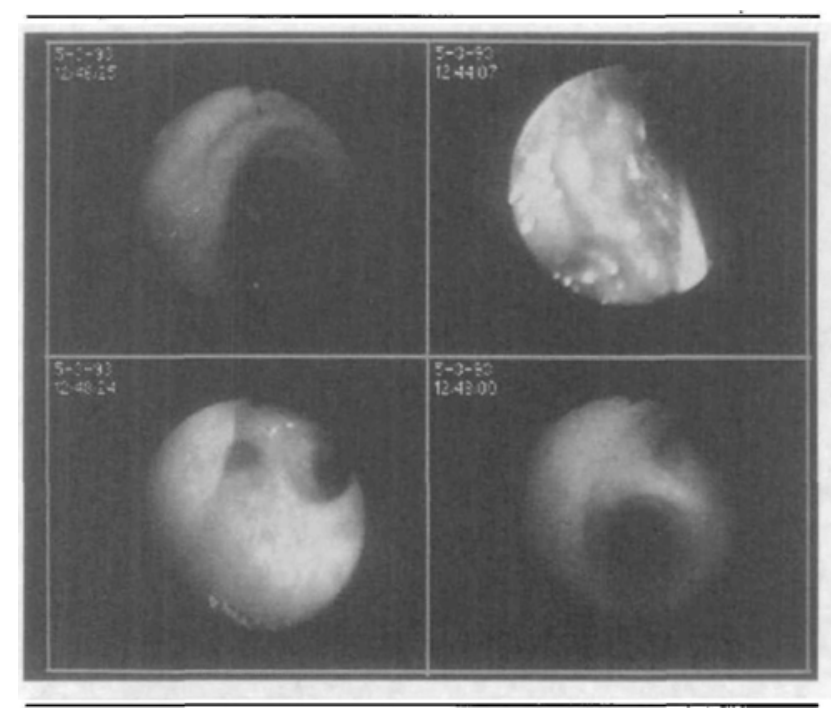

FIGURE 1 Recovery room bronchoscopy at 1230 showing diffuse punctate haemorrahges throughout the trachea and both mainstem bronchi. Upper left panel - right mainstem bronchus (the right upper lobe bronchus is at the bottom of the panel); upper right panel - within the tracheal tube; lower left panel - left mainstem bronchus above the bifurcation of the lingula and left lower lobe; lower right panel trachea just above the left of the carina.

graphs (Video adapter OTV-G2, Olympus, Dallas, Tx; Sony Mavigraph) were taken (Figure 1). The mucosa of the trachea and both mainstem bronchi were lined with numerous punctate haemorrhagic lesions. There was persistent bleeding from these lesions. A post-bronchoscopy chest radiograph was consistent with the typical findings associated with post-obstructive acute pulmonary oedema and significantly different than the admission film. ${ }^{3}$

In the surgical intensive care unit (SICU) the patient was treated with mechanical ventilation, supplemental oxygen and positive end-expiratory pressure. The trachea was suctioned every four hours.

Considerable improvement in oxygenation and ventilation occurred by the second SICU day and the trachea was extubated without further complications.

\section{Discussion}

This is the first case of post-obstructive NPPE that has been photographed bronchoscopically demonstrating large airway mucosal haemorrhages. Our case fits the typical clinical picture of abrupt onset pulmonary oedema following airway obstruction in a young adult with rapid resolution within $24 \mathrm{~h}^{1}$ The majority of adult cases of NPPE have been attributed to laryngospasm presenting as reflex glottic closure as a result of either intrinsic or extrinsic laryngeal stimuli, ${ }^{6,7}$ Inspiratory efforts against an obstructed upper airway result in the development of negative intrathoracic and transpulmonary pressures (Mueller manoeuvre).$^{6-9}$ (Figure 2) 


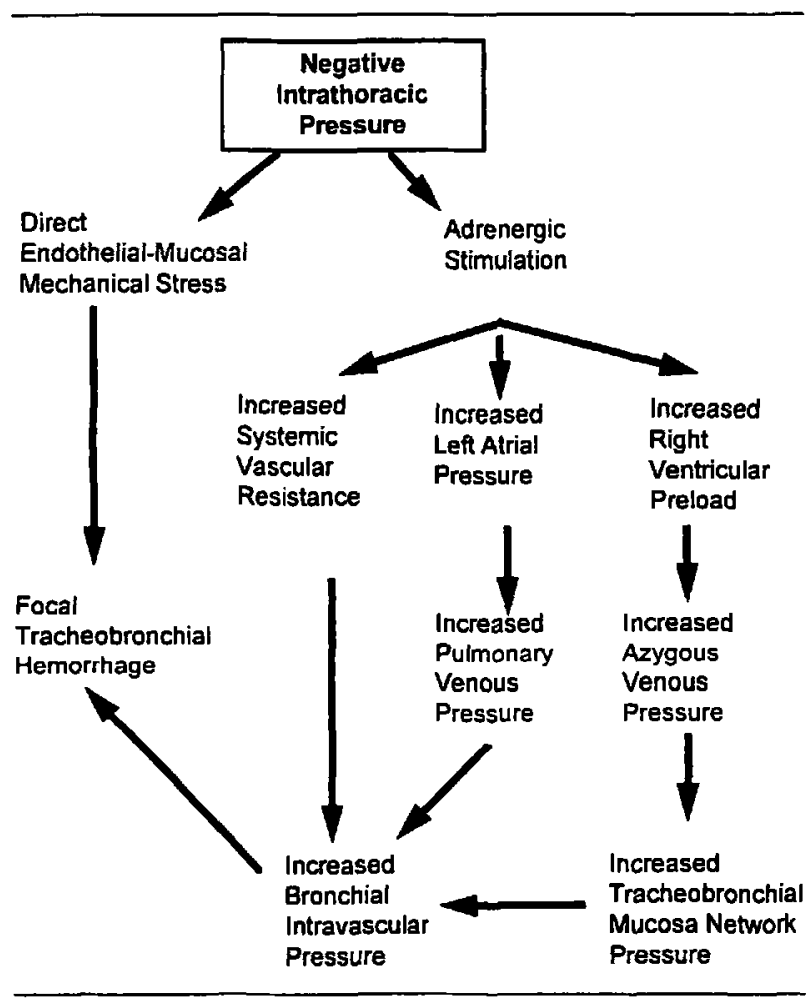

FIGURE 2 Proposed mechanisms for development of pulmonary oudemá postobstructive.

There are three possible mechanisms for the development of NPPE and all relate directly to the development of negative intrapleural pressure. 'These describe neurogenic (hyperadrenergic), cardiac, and/or hydrostatic (pulmonary) mechanisms producing NPPE. ${ }^{1.10}$

Normal quiet breathing produces inspiratory intrapleural pressures ranging from -2 to $-5 \mathrm{~cm} \mathrm{H}_{2} \mathrm{O}$ and expiratory pressures of $+10 \mathrm{~cm} \mathrm{H}_{2} \mathrm{O}$. However, peak inspiratory effort can produce pressures as low as -100 to $-140 \mathrm{~cm} \mathrm{H}_{2} \mathrm{O} .{ }^{11}$ Maximum intrapleural pressures of $-51 \mathrm{~cm} \mathrm{H}_{2} \mathrm{O}$ and $-67 \mathrm{~cm} \mathrm{H}_{2} \mathrm{O}$ have been shown in asthmatics and adults with upper airway obstruction, respectively. ${ }^{12.13}$

The observed and postulated clinical effects of large negative intrapleural pressures are varied and affect several organ systems. Breakdown of the alveolar-capillary membrane occurs. ${ }^{1,2,4}$ Membrane disruption leads to leakage of fluid into the gas exchanging units of the lung. This exudative process produces a high protein concentration in the oedema fluid relative to that in plas$\mathrm{ma}$ and is considered the hallmark of the hydrostatic (pulmonary) model of NPPE. ${ }^{1.4,10}$ In addition to leakage into the alveoli, injury to the pulmonary capillary bed allows transudation of serum proteins from the pulmonary capillary space into the pulmonary interstitial space, further increasing oedema fluid protein content. In animals, a high ratio of oedema fluid to serum protein concentration has been reported in increased permeability oedema $(0.98 \pm 0.05)$, whereas lower values have been reported in neurogenic oedema $(0.48$ to 0.84$)$ and in haemodynamic oedema $(0.54 \pm 0.04) .{ }^{14}$ Dohi et al. ${ }^{15}$ reported a case of NPPE secondary to bilateral vocal cord paralysis in which the high protein content of the oedema fluid was consistent with increased permeability. In addition, mechanical stress that develops during respiration against an obstructed upper airway may further contribute to direct pulmonary capillary injury. ${ }^{16.17}$

Negative intrapleural pressures redistribute blood from the systemic venous to the pulmonary circulation resulting in an increase in pulmonary blood volume. ${ }^{1,6}$ In experimental animals this increase in pulmonary blood volume has been associated with an increase in pulmonary lymph flow which would support the concept that hydrostatic processes contribute to the production of NPPE. ${ }^{18}$

Negative intrapleural pressure affects cardiac function directly. In animals, Robotham et al..$^{19}$ demonstrated increased left ventricular filling pressures during the Mueller manoeuvre. However, they did not find increased pulmonary blood volume and they postulated that the changes they observed were due to increased sympathetic tone and its affects on the cardiovascular system. Subsequently Buda et al. ${ }^{20}$ demonstrated that negative intrathoracic pressure $\left(-60 \mathrm{~cm} \mathrm{H}_{2} \mathrm{O}\right)$ increased left ventricular preload and afterload, decreased the ejection fraction, and increased left ventricular end systolic volume by $18-25 \%$.

Hypoxia associated with the development of NPPE produces pulmonary vasoconstriction, resulting in increased pulmonary vascular resistance. ${ }^{21}$ Blood redistribution, decreased perivascular interstitial hydrostatic pressure (dilutional effect), decreased pulmonary vascular transmural pressures (arterial, capillary, and venous), and increased pulmonary intravascular pressures all promote increased pulmonary capillary hydrostatic pressure and thus promote oedema fluid exudation into the pulmonary interstitium and gas exchanging units. Increased pulmonary intravascular pressures may also rupture pulmonary capillaries producing focal haemorrhages. ${ }^{4}$

The pulmonary circulation comprises both the pulmonary and bronchial vasculatures. The pulmonary vasculature is primarily a low-pressure system whose resistance can be affected by oxygen tension. Conversely, the bronchial circulation is a high pressure system contiguous with the systemic arterial circulation. Changes in bronchial vascular resistance could mirror alterations in systemic vascular resistance. The bronchial arteries supply the trachea, bronchial, and bronchiolar walls. The bronchial circulation forms a vascular network in the tracheobronchial mucosa as far distally as the terminal bronchioles. The network drains into the right heart 
via the azygous venous system and into the left atrium via extensive anastamoses with the pulmonary circulation at the pre-capillary, capillary, and post-capillary sites and subsequently into the left atrium by the pulmonary veins. ${ }^{22,23}$

The variety of experimental and clinical effects demonstrated by negative intrathoracic pressure support a multifactorial process with an interplay between hydrostatic (pulmonary), neurogenic (hyperadrenergic), and cardiac systems.' This interplay could have produced the focal haemorrhages that we observed. The punctate haemorrhages may be representative of a hyperadrenergic state. Increased right and left heart pressures and increased systemic and bronchial vascular resistance contribute to increased bronchial intravascular pressure. This pressure could be reflected in the mucosal vascular network described previously and directly lead to loss of vascular integrity. Loss of vascular integrity could present as focal haemorrhages throughout the larger airways. Therefore, our findings may reflect changes in the systemic-bronchial circulation rather than any disruption of the more distal alveolar-capillary system. We believe the photomicrographs showing diffuse punctate haemorrhages represent bronchial mucosal network disruption. Disruption of small vessels in patients with NPPE has been suggested by others but not demonstrated bronchoscopically as in our case. 1.4 $^{-4}$

In summary, we present a patient with acute post obstructive NPPE in whom photographs of the tracheobronchial mucosa demonstrate diffuse punctate haemorrhages which may contribute to the clinical presentation of frothy pink secretions. Our findings suggest that the punclate haemorrhages seen represent disruption of the bronchial vasculature.

\section{References}

1 Lang SA, Duncan PG, Shephard DAE, Ha HC. Pulmonary oedema associated with airway obstruction. Can J Anaesth 1990; 37: 210-8.

2 Timby J, Reed C, Zeilender S, Glauser FL. "Mechanical" causes of pulmonary edema. Chest 1990; 98: 973-9.

3 Cascade PN, Alexander GD, Mackie DS. Negative-pressure pulmonary edema after endotracheal intubation. Radiology 1993; 186: 671-5.

4 Staub NC. The pathogenesis of pulmonary edema. Prog Cardiovasc Dis 1980; 23: 53-80.

5 Warner LO, Beach TP, Martino D. Negative pressurc pulmonary oedema secondary to airway obstruction in an intubated infant. Can J Anaesth 1988; 35: 507-10.

6 Lorch DG, Sahn SA. Post-exlubation pulmonary edema following anesthesia induced by upper airway obstruction: are certain patients at increased risk? Chest 1986; 90: 802-5.
7 Willms D, Shure D. Pulmonary edema duc to upper airway obstruction in adults. Chest 1988; 94: 1090-2.

$8 \mathrm{Kollef} \mathrm{MH}$, Pluss $J$. Noncardiac pulmonary edema following upper airway obstruction. 7 cases and a review of the literature. Medicine 1991; 70: 91-8.

9 Jackson FN, Rowland V, Corssen $G$. Laryngospasminduced pulmonary edema. Chest 1980; 78: 819-21.

10 Holmes JR, Hensinger RN, Wojtys EW. Postoperative pulmonary edema in young, athletic adults. Am J Sports Med 1991; 19: 365-71.

11 Rahn H, Otis AB, Chadwick LE, Fenn WO. The pressurevolume diagram of the thorax and lung. Am J Physiol 1946; 146: 161-78.

12 Stalcup SA, Mellins RB. Mechanical forces producing pulmonary edema in acute asthma. N Engl J Med 1977; 297: 592-6.

13 Newton-John $H$. Pulmonary oedema in upper airway obstruction (Letter). Lancet 1977; 2: 510.

14 Maron MB. Analysis of airway fluid protein concentration in neurogenic pulmonary edema. J Appl Physiol 1987; 62: 470-6.

15 Dohi S, Okubo N, Kondo $Y$. Pulmonary oedema after airway obstruction due to bilateral vocal cord paralysis. Can J Anaesth 1991; 38: 492-5.

16 McGonagle $M$, Kennedy $T L$. Laryngospasm induced pulmonary edema. Laryngoscope 1984; 94: 1583-5.

17 Matsuura Y, Nomimura T, Murakami H, Matsushima T, Kakehashi $M$, Kajihara $H$. Clinical analysis of reexpansion pulmonary edema. Chest 1991; 100: 1562-6.

18 Loyd JE, Nolop KB, Parker RE, Roselli RJ, Brigham $K L$. Effects of inspiratory resistance loading on lung fluid balance in awake sheep. J Appl Physiol 1986; 60: 198-203.

19 Robothain IL, Stuarl RS, Doberty K, Borkon AM, Baumgartner $W$. Mitral and aortic blood flows during spontaneous respiration in dogs. Anesthesiology 1988; 69: 516-26.

20 Buda AJ, Pinsky MR, Ingels NB, Daughters CT, Stinson $E B$, Alderman $E L$. The effect of intrathoracic pressure on left ventricular performance. N Engl J Med 1979; 301: 453-9.

21 Moss G, Staunton C, Stein AA. The centrineurogenic etiology of acute respiratory distress syndromes. Universal, species-independent phenomenon. Am J Surg 1973; 126: 37-41.

22 Deffebach $M E$, Widdicombe J. The bronchial circulation. In: Crystal RG, West JB (Eds.). The Lung: Scientific Foundations. New York: Raven Press Ltd., 1991: 741-57.

23 Nunn JF. The pulmonary circulation. In: Nunn's Applicd Respiratory Physiology. 4th ed. Oxford: ButterworthHeinemann, 1993: 135-55. 